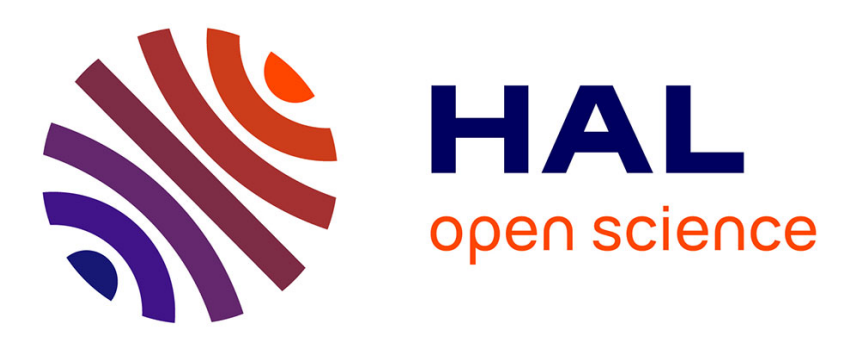

\title{
Cervical laminectomy and micro resection of the posterior venous plexus in Hirayama disease.
}

Pierre Brandicourt, José Cuesta Del Sol, Sorin Aldea, Fabrice Bonneville, Pascal Cintas, David Brauge

\section{To cite this version:}

Pierre Brandicourt, José Cuesta Del Sol, Sorin Aldea, Fabrice Bonneville, Pascal Cintas, et al.. Cervical laminectomy and micro resection of the posterior venous plexus in Hirayama disease.. Neurochirurgie, 2018, 64 (4), pp.303-309. 10.1016/j.neuchi.2018.04.004 . hal-02496565

\section{HAL Id: hal-02496565 \\ https://hal.science/hal-02496565}

Submitted on 3 Mar 2020

HAL is a multi-disciplinary open access archive for the deposit and dissemination of scientific research documents, whether they are published or not. The documents may come from teaching and research institutions in France or abroad, or from public or private research centers.
L'archive ouverte pluridisciplinaire HAL, est destinée au dépôt et à la diffusion de documents scientifiques de niveau recherche, publiés ou non, émanant des établissements d'enseignement et de recherche français ou étrangers, des laboratoires publics ou privés. 


\title{
Cervical laminectomy and micro resection of the posterior venous plexus in Hirayama disease
}

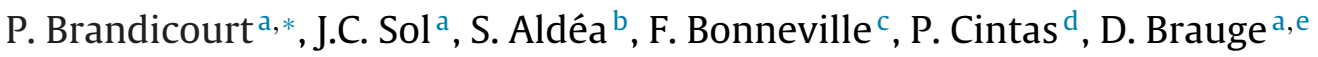 \\ a Service de Neurochirurgie, pôle Neuroscience, centre hospitalo-universitaires de Toulouse, université de Toulouse, UPS, 31000 Toulouse, France \\ b Service de Neurochirurgie, hôpital Foch, 92150 Suresnes, France \\ ' Service de Neuroradiologie, pôle Neuroscience, centre hospitalo-universitaires de Toulouse, université de Toulouse, UPS, 31000 Toulouse, France \\ d Service de Neurologie, pôle Neuroscience, centre hospitalo-universitaires de Toulouse, université de Toulouse, UPS, 31000 Toulouse, France \\ e Institut de Biomécanique Humaine Georges Charpak Arts et Métiers Paris Tech, 75013 Paris, France
}

Keywords:

Hirayama disease

Cervical myelopathy

Laminectomy

Flexion MRI

\begin{abstract}
A B S T R A C T
Introduction. - Hirayama disease is a rare cervical myelopathy predominantly affecting young adults and mainly found in Asia. It results in a pure motor distal lesion of the upper limbs with slow progression. Dynamic magnetic resonance imaging (MRI), which allows the diagnosis to be made, shows a typical appearance of anterior compression of the cervical spinal cord associated with enlargement of the posterior epidural spaces due to a dilated venous plexus. Surgery is considered when conservative treatment has failed. However, the type of surgery is not well standardized in this compressive myelopathy.

Methods. - We report on three patients with Hirayama disease operated using an original method: cervical decompressive laminectomy and coagulation of the posterior epidural plexus without fixation. The clinical, radiological and surgical data of these three patients were analyzed. Each patient underwent postoperative MR imaging.

Results. - The mean age at diagnosis was 18.6 years (16-20 years) with a history of progressive symptoms lasting 1 to 4 years before treatment. Follow-up was 21 to 66 months after surgery. Neurological and electrophysiological improvement was noted in two patients; the third had stabilized. Postoperative MRI confirmed normalization of flexion imaging on MRI. None of the three patients complained of disabling neck pain.

Conclusion. - Posterior cervical decompression with coagulation of epidural venous plexus is a technique that seems effective in Hirayama disease in young subjects. It effectively treats patients by avoiding permanent cervical fixation.
\end{abstract}

\section{Introduction}

Hirayama disease was described in 1959 by a Japanese neurologist and is a well-known cause of lower cervical myelopathy in Asian countries [1]. A Japanese survey found a prevalence estimated at $1 / 30,000$ people [2]. Several cases or small series of patients have been reported in Europe and America [3-7] but the incidence remains unknown in non-Asian countries. The disease preferentially affects young men between 15 and 20 years of age and is characterized by muscle weakness and atrophy in the distal portion of one or both upper limbs [8]. Installation is progressive and painless, without long tract signs. Presentation is most often unilateral at the beginning but bilateral involvement occurs during the progression of the disease in up to one third of patients [2]. It mainly affects the metameric territories of C7-T1. The brachioradial muscle, with C6 innervation, is classically spared, which results in a clinical presentation of oblique atrophy [9]. The course of the disease is characterized by gradual worsening of symptoms until stabilization occurs after several years of progression [8]. While it is a nonlethal disease, its clinical consequences can be extremely disabling for patients [8]. Several differential diagnoses among motor neuron diseases must be considered, such as amyotrophic lateral sclerosis (rare in young subjects), multifocal motor neuropathy and spinal muscular atrophy. Electroneuromyography studies (ENMG) can be helpful in supporting the diagnosis, since a low ulnar/medial compound muscle action potential (CMAP) ratio in the $\mathrm{C} 7$ to $\mathrm{T} 1$ territories is suggestive of Hirayama disease [10]. Magnetic resonance imaging (MRI) can reveal atypical signs such as cord atrophy or intramedullary hyperintensity on T2-weighted images [11]. Finally, the diagnosis 
is confirmed if flexion MRI shows spinal cord compression by posterior dilated venous plexus and forward shift of the dura [11].

Surgical treatment is generally considered for advanced disease [9]. The choice of surgical technique is, however, debated. We report three European cases of rapidly progressing Hirayama disease treated by an original technique consisting of laminectomy and microcoagulation of the posterior epidural venous plexus.

\section{Materials and methods}

We present a retrospective series of three patients treated in the same center for Hirayama disease. The diagnosis was confirmed after complete neurological assessment. All patients were operated by the same surgeon. Clinical follow-up was done by the senior author and two assistants qualified in the review of clinical and radiological data related to spinal surgery.

\subsection{Surgical technique}

The patient was positioned prone, attached to a Mayfield headrest in slight cervical flexion. After making an incision on the midline and detaching the muscles, cervical laminectomy was performed carefully and extended over the stenosed levels (defined by cervical dynamic flexion MRI). A large dilated venous plexus was found in all cases in the posterior epidural space and was gradually and gently coagulated, with progress being followed under the microscope, until the posterior part of the dura mater was fully exposed. Blood loss was closely monitored. Depending on the decompression quality, duraplasty was carried out in addition to laminectomy. Once the cervical decompression was completed, hemostasis was progressively achieved using hemostatic gauze and bipolar coagulation. No fixation was used and the incision was closed carefully.

\subsection{Evaluation of outcomes}

Clinical evaluation was performed through pre- and postoperative motor testing using the standard neurological classification of spinal cord injury (ASIA Score). Patients with a clinical improvement of one point on two or more metameres were considered as improved. At the last follow-up, cervical neck pain and disability were evaluated on a Visual Analog Scale (VAS) and the Neck Disability Index (NDI), respectively. Radiological evaluation focused on the quality of the spinal cord decompression based on the reappearance of cerebrospinal fluid (CSF) around the spinal cord in flexion MRI 1 year after surgery. We also looked for signs of instability on dynamic MRI sequences. Electrophysiological evaluation used the median/ulnar CMAP ratios and the sum of the ulnar and median CMAP between pre- and postoperative measurements.

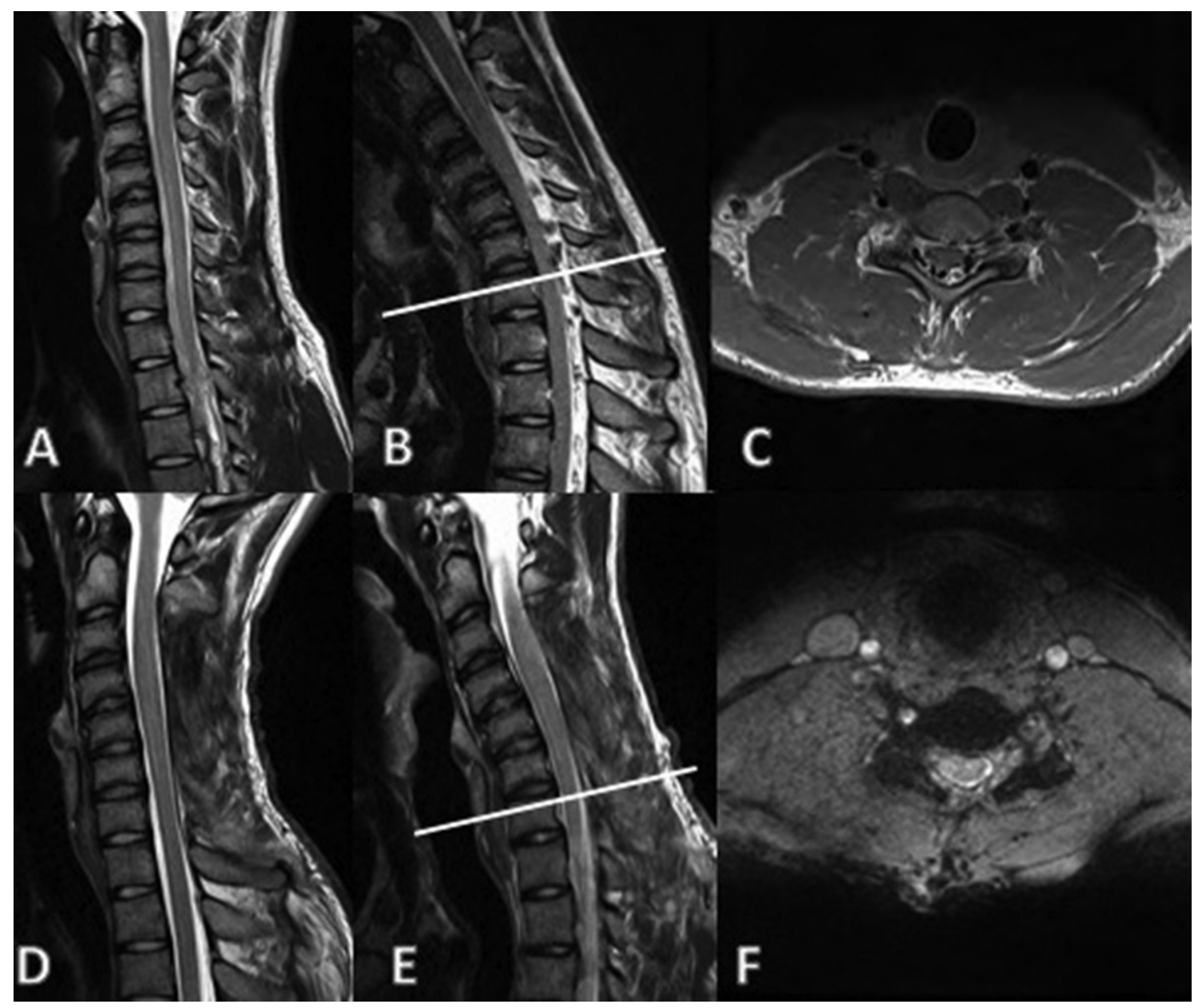

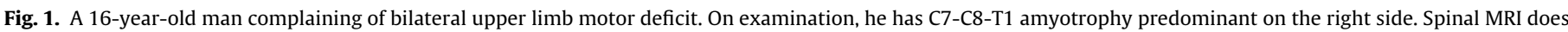

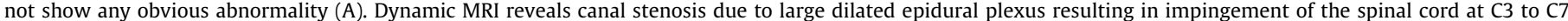

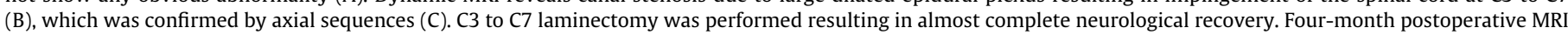

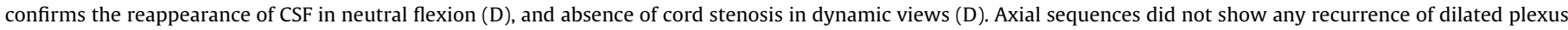
(E). 


\section{Results}

\subsection{Case 1}

The first case was a 16-year-old man who had an asymmetrical amyotrophic deficit of the upper limbs for 1 year in the $\mathrm{C7}$ to T1 territories, evaluated at $2 / 5$ on the right side and $4 / 5$ on the left side. This deficit appeared gradually and painlessly. Its only precursor was scoliosis. Electrophysiological data showed active, chronic denervation in the C7-T1 myotomes with an abnormally high median/ulnar CMAP ratio of 2.43. Cervical MRI was considered sub-normal with slight cervical canal narrowing (Fig. 1). Hirayama disease was suggested in view of the clinical symptoms and a dynamic MRI was requested. In cervical flexion, enlargement of the posterior epidural spaces and dilated vertebral venous plexuses at the C3 to C6 level were seen. This venous engorgement was responsible for spinal cord compression because of the disappearance of perimedullary fluid spaces.

A C3-C6 laminectomy with duraplasty and plexus resection was performed to decompress the spinal cord. During the surgery, which lasted 330 minutes, significant bleeding complicated the decompression $(850 \mathrm{~mL})$.

The clinical course was favorable. At 3 years after surgery, the patient had only a right-hand deficit evaluated at $2 / 5$ on $5^{\text {th }}$ finger abduction. Other motor deficits had completely resolved. He did not complain of cervical pain $(\mathrm{VAS}=0)$ and his NDI was 4/50. Postoperative electrophysiological assessment confirmed his recovery with an increase in the sum of the ulnar and median CMAP between pre-and postoperative measurements and median/ulnar CMAP ratio decrease during follow-up. MRI scans at 6 months and 2 years postoperative confirmed the reappearance of CSF around the cord. Dynamic sequences showed no signs of instability (Fig. 1). This patient was able to successfully complete his studies.

\subsection{Case 2}

A 17-year-old patient had been suffering from a motor distal deficit of the upper right limb for 6 months, with progressive installation associated with amyotrophy of the forearm. He had no related personal or family medical history and his symptoms were not accompanied by pain. There was no pyramidal sign. Antiganglioside antibodies were measured because multifocal motor neuropathy with conduction block was suspected in view of the clinical presentation, but the results were negative. Cervical MRI found essentially a straightness of the cervical spine with C4-C5 and C5-C6 discopathy, responsible for a small stenosis without associated myelopathy (Fig. 2).

Given the development of the disorder, the pure motor impairment, and the absence of extension of the neurogenic anomalies to the contralateral limb, the patient was treated for a motor neuropathy with conduction block despite the absence of anti-ganglioside antibodies.

After 3 years of exploration and several immunoglobulin courses, the patient experienced rapid clinical worsening with the appearance of a left thumb and left index finger extensor palsy graded at $4 / 5$. Standard MRI was performed and showed an intramedullary hypersignal on T2-weighted sequence at the C4C5 level (Fig. 2). There was discopathy at C5-C6 but no evidence of spinal cord compression. He reported no history of trauma. We therefore decided to carry out a supplementary dynamic MRI. In cervical anterior flexion, the perimedullary spaces disappeared and posterior contrast enhancement was observed from C4 to C7, indicating the presence of posterior epidural venous plexus. Imaging was highly suggestive of Hirayama disease.

Because of the rapid progression, surgical management was decided. A C4-C7 laminectomy and duraplasty was performed with coagulation of the posterior venous plexus, with an operative time of $290 \mathrm{~min}$. This surgery was marked by significant bleeding

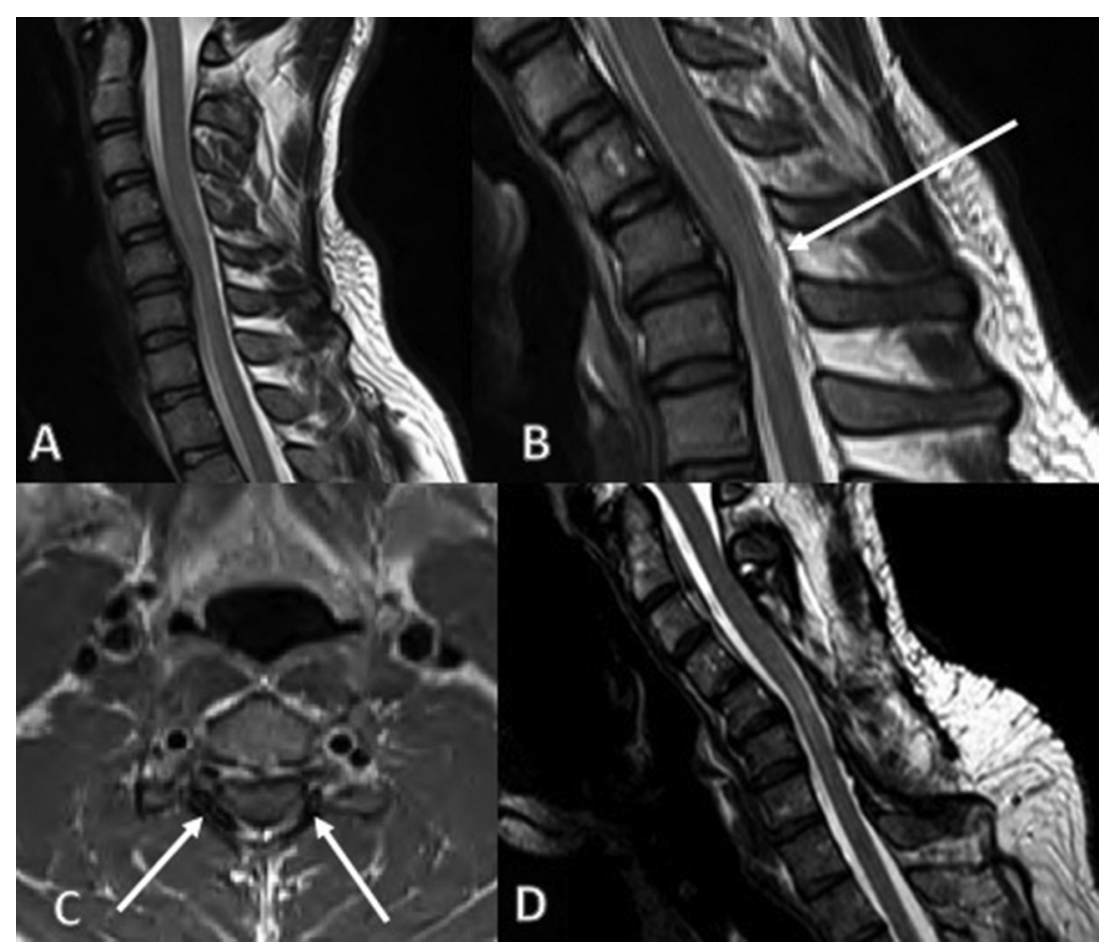

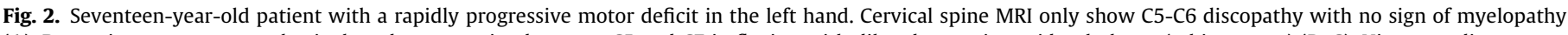

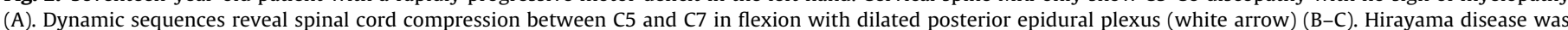

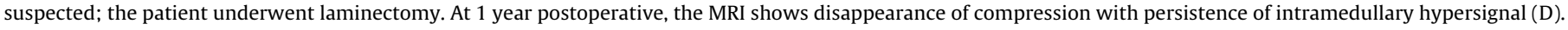




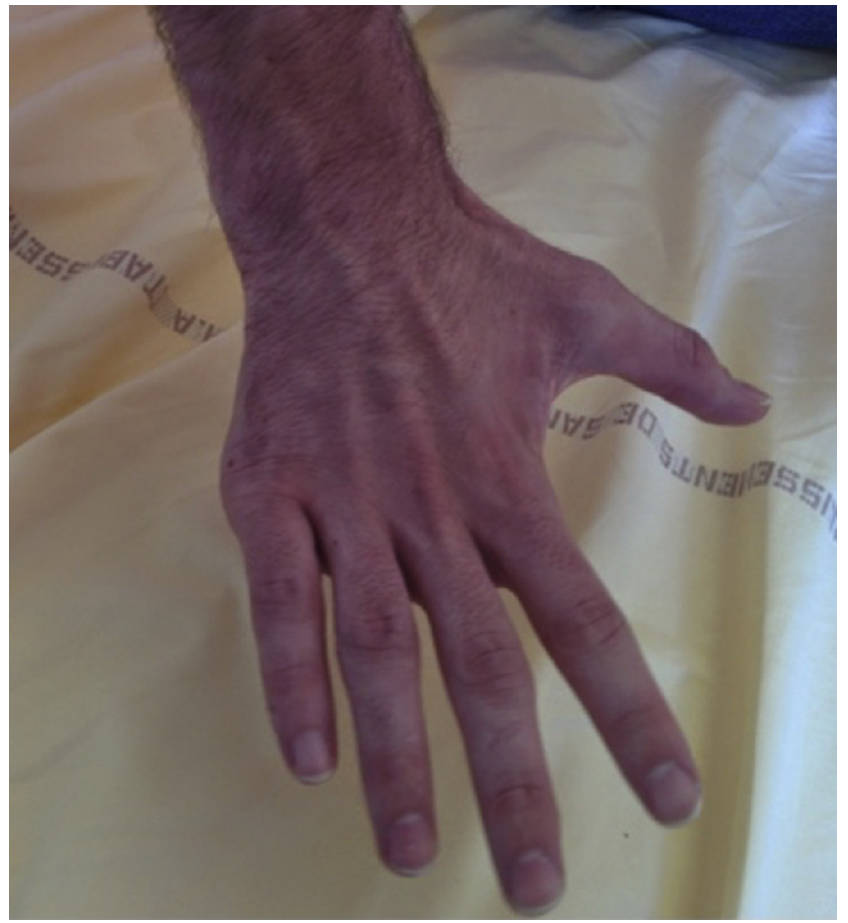

Fig. 3. Amyotrophy of the right hand of a young patient with Hirayama disease before treatment.

$(1400 \mathrm{~mL})$. The disease progression stopped after surgery. At final follow-up, 3 years after the treatment, neurological assessment confirmed clinical stabilization. The patient reported no cervical pain $(\mathrm{VAS}=0$ ) and had an NDI at $1 / 50$. No change was observed in the electrophysiological assessment. Postoperative MRI showed CSF around the spinal cord with persistence of intramedullary hypersignal in T2-weighted sequence (Fig. 2).

\subsection{Case 3}

The last case concerned a young man, 20 years of age, who was an amateur rugby player. He consulted because of a distal deficit of the upper limb that had gotten progressive worse over 8 months. The clinical examination found bilateral distal amyotrophy of the upper limb and distal motor deficit graded at 4/5 on right thumb opposition and 2/5 on right thumb adduction (Fig. 3 ). On the left side, opposition and adduction of the thumb were $4 / 5$ and $3 / 5$, respectively. The rest of the exam was normal. Electrophysiological data showed absence of conduction blocks on motor nerve studies and $\mathrm{C} 7$ to $\mathrm{T} 1$ chronic denervation but an abnormally high median/ulnar CMAP ratio of 7.4. Hirayama disease was confirmed by dynamic MRI showing anterior displacement of the spinal cord and the dural sac in anterior flexion, with enlargement of the posterior dural space due to dilated veins from $\mathrm{C} 4$ to $\mathrm{C} 7$. The diagnosis was confirmed and C3-C7 laminectomy was performed rapidly. During surgery, dilated venous plexuses were found that were carefully coagulated. Operative time was $299 \mathrm{~min}$ with little bleeding (about $250 \mathrm{~mL}$ ). At the final follow-up, clinical assessment of the patient was favorable with stability of the right distal motor deficiency and improvement of the left motor deficiency with adduction of the thumb at $4+/ 5$. NDI and VAS were $6 / 50$ and $0 / 10$, respectively. The high median/ulnar ratio decreased based on ENMG. Postoperative MRI at 1 year showed marked radiological improvement with disappearance of posterior epidural venous dilatation and reappearance of CSF around the spinal cord (Fig. 4). At 2 years, dynamic cervical radiography confirmed the absence of instability (Fig. 5). The patient was satisfied with the surgery. He could resume his professional activities but not rugby, which was contraindicated by the surgeon.

\section{Discussion}

In the present study, we have described the use of a non-fusion technique in young patients with Hirayama disease. In these 3 cases treated at our hospital, two patients experienced clinical

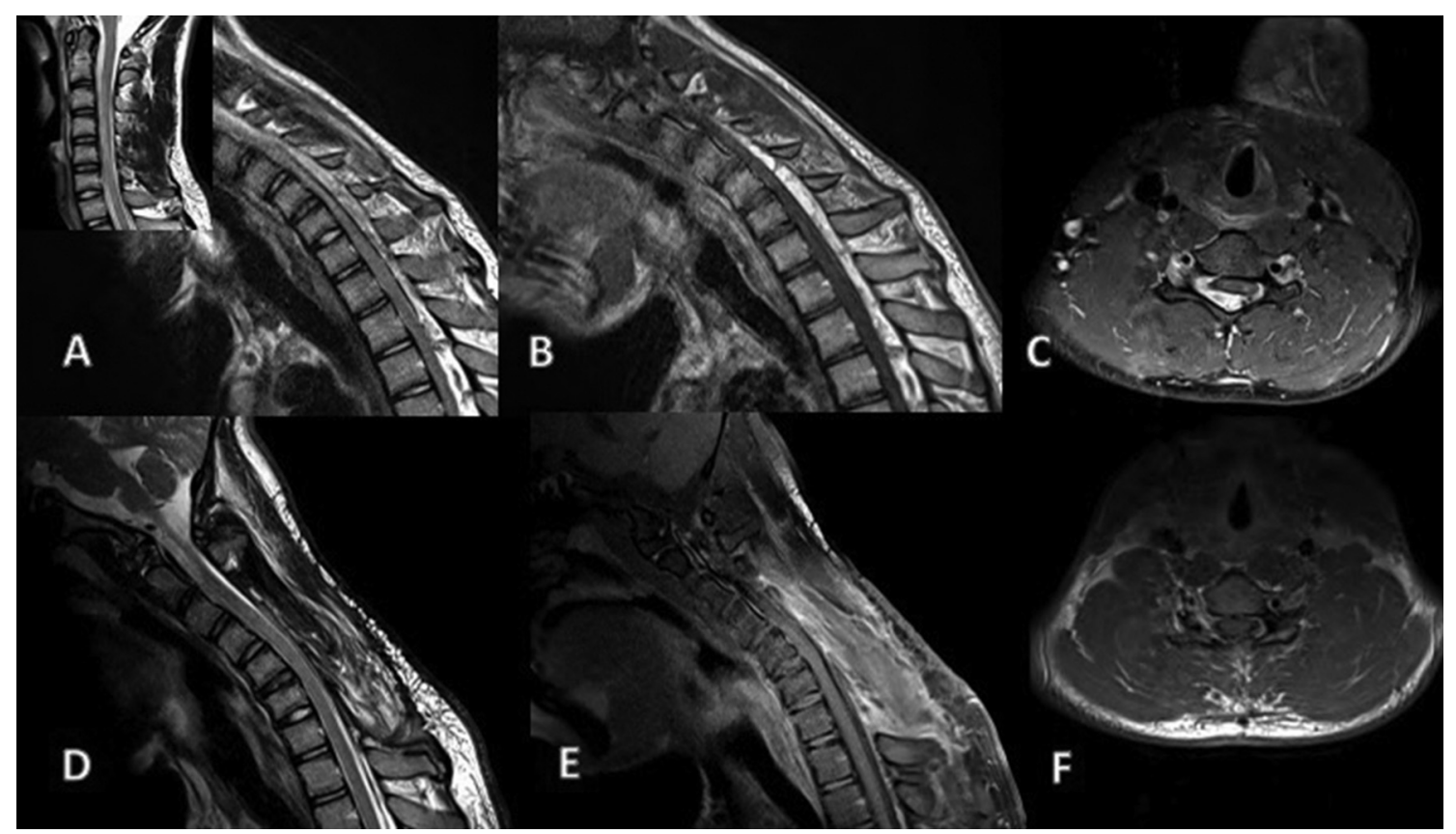

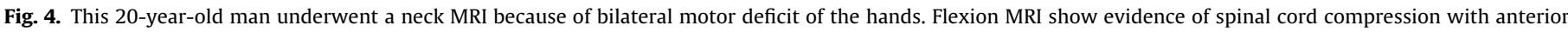

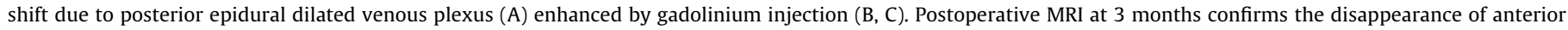
displacement and reappearance of CSF around the spinal cord (D, E, F). 


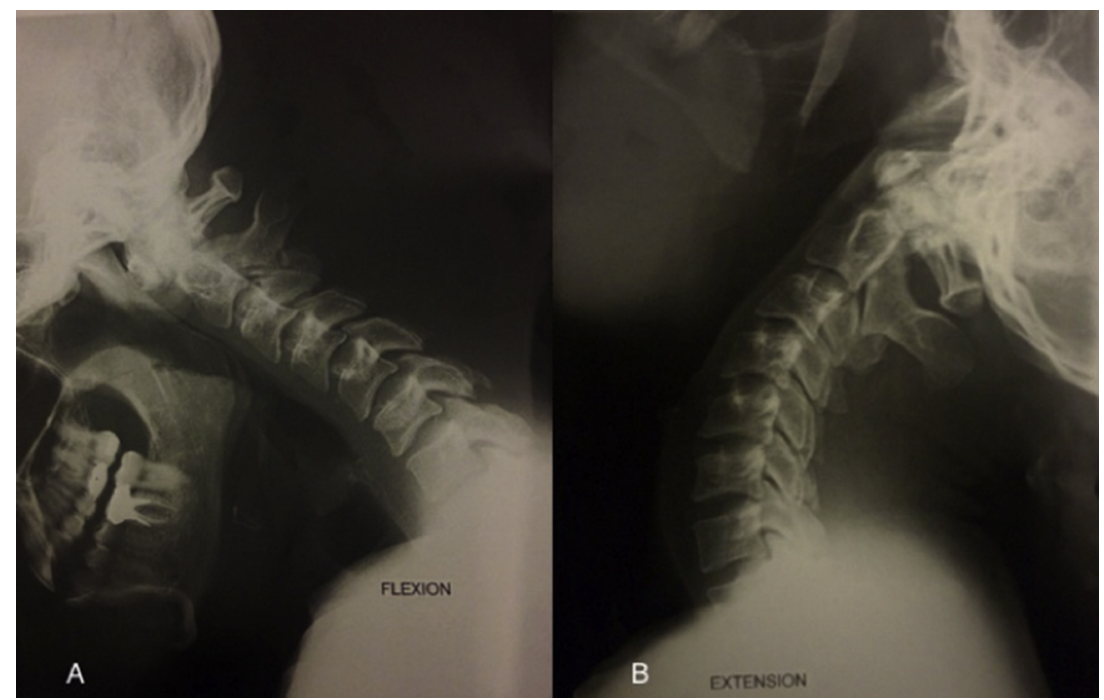

Fig. 5. Postoperative dynamic X-rays at 2 years confirm the dynamic MRI findings with conservation of mobility without instability in flexion (A) and extension (B).

and electrophysiological improvement. The third one had stabilized despite a rapidly worsening condition preoperatively. This latter case was also the patient with the longest preoperative disease duration. In all cases, postoperative dynamic MRI confirmed reappearance of spinal CSF spaces and disappearance of the dilated epidural plexus without associated instability. These data suggest that surgery improved or stabilized their functional capacity. At the last follow-up, none of the three patients report disabling neck pain with VAS at 0 and $\mathrm{NDI} \leq 6$.

\subsection{Pathophysiology of Hirayama disease}

Although Hirayama disease is a well-known and documented disease in Asian countries, its pathophysiology remains unclear [12]. A study in Taiwan found that one-third of patients were engaged in intense physical activity [13]. The role of this activity as a triggering factor is debated. Sports, such as gymnastics, dance or the intensive practice of music, with their repeated cervical flexion movements, might contribute to the development of this disease. In our study, one patient played rugby regularly and one was a highlevel cellist. At the present time, no genetic predisposition has been highlighted [14] but familial cases have been reported [15].

There are several theories about the cause of this disease. In healthy subjects, the spinal cord is not compressed against the posterior wall of the vertebral bodies during cervical flexion. The dura mater is adaptable and follows vertebral movements without deformation. In Hirayama disease, the posterior aspect of the dura mater falls off the posterior wall of the vertebral canal in flexion. The spinal cord is then pushed forward and crushed, which in turn causes chronic ischemic lesions. An autopsy of a patient with Hirayama disease found ischemic lesions of the anterior horns of the spinal cord, which explained the muscle weakness and atrophy in the distal portion of the upper limbs without pain [16]. A lack of dura mater elasticity may cause this anterior shifting. Konno studied the histology of this dura mater [17]. He found a loss of elastin and a decrease in the wavy appearance of the elastic tissues. Others have suggested that dura mater and spinal column growth are disproportionate in Hirayama disease: the cervical spine growths faster than dura mater, which loses elasticity. Since spine growth in boys is faster than in girls, it could explain why the disease is predominant in males [18]. This "flexion theory" results in repetitive microtrauma to the anterior portion of the spinal cord [19].
However, this theory does not explain the hyperdilated venous plexus seen on MRI. Another hypothesis was put forward by Hirayama himself [9]: it argues that ischemia may result not only from direct traumatic lesions during flexion but also from increased intramedullary pressure which would lead to local microcirculation disorders and spinal compression. Venous stagnation in the posterior epidural plexus, seen on dynamic MRI, increases microcirculatory disorders in flexion and spinal cord compression. We chose to treat our patients by acting on the compressive nature of this pathology. While the pathophysiology is likely multifactorial, our results suggest that dilated plexuses participate in Hirayama disease.

\subsection{Radiological and electrophysiological data in Hirayama disease}

Advances in radiology, including magnetic resonance, have helped to better describe the signs encountered in this pathology [11]. MRI has become the key element in the diagnosis of Hirayama disease. In the neutral position, MRI of the cervical spine is often considered normal as it shows only some slight radiological evidence of the disease: straightness of the cervical spine with loss of lordosis, C5-C6 atrophy, deformation of the anterior part of the spinal cord, and intramedullary hypersignal on T2-weighted images. Flexion MRI helps to confirm the diagnosis: anterior displacement of the posterior dura with detachment of the posterior wall of the canal, enlargement, posterior flow void due to dilated venous plexus and contrast enhancement of the posterior epidural space by venous plexus and disappearance of CSF spaces are typical radiological signs [11]. These radiological signs tend to disappear with the progression of the disease and are observed less 10 years after the onset of symptoms, which would explain the clinical stabilization phase observed at the end of several years of progression [8]. One case of thoracic compression was reported in the literature, [20] Jin studied the electrophysiological differences between Hirayama disease, amyotrophic lateral sclerosis and cervical spondylosis amyotrophy [10]. These studies found a significantly lower ulnar/median CMAP ratio in Hirayama disease. Electrophysiological data in our patients confirm the lack of sensory nerve conduction abnormalities in the upper limbs and the lack of motor nerve conduction blocks. Needle electromyography has confirmed active and chronic denervation confined to C7-T1 myotomes. We used the sum of the ulnar and median CMAP 
between pre-and postoperative measurements at the last followup. For two of the three patients, an increase in this sum was noted (mean $1.65 \mathrm{~V}$ ) and was correlated with their clinical improvement. Similarly, the abnormally high median/ulnar CMAP ratio decreased in these two patients.

\subsection{Treatment of Hirayama disease}

There is no consensus on the treatment for this disease. In the literature, most patients received non-surgical treatment with a cervical collar to prevent repetitive injuries of the anterior spinal cord during flexion movements [21]. This alternative seems to stabilize the disease, at the cost of long-term treatment lasting 3 to 4 years [8] and should be reserved for patients with few clinical symptoms at the onset of disease. Surgery is indicated for symptomatic patients, especially when the diagnosis has been delayed (due to lack of recognition of this pathology in non-Asian countries, for instance) [8]. Because of the dynamic nature of the disease, most authors describe a fusion procedure. The most commonly used are anterior fusion or posterior fixation with or without laminectomy to permanently block cervical flexion $[22,17,23]$. Goel extend this fusion to atlanto-axial joint in the five cases he reported [23]. However, other techniques have been described in the literature. For Watanabe, anterior decompression and interbody fusion led to improvements in 12 patients [23]. Kohno used this technique in six patients with good results and clinical stabilization [22]. Five patients were stabilized by posterior fusion and duraplasty in Konno's series [17]. Hito has published a new technique that consists of performing a duraplasty by laminotomy without fusion [24]. Used in 6 patients, it stopped the progression of the disease in the postoperative period but the technique seems difficult to perform and time consuming (more than 6 hours for each patient), with a risk of CSF leak ( 1 case out of 6 patients). In the event of severe muscular atrophy linked to a long progression of the disease, musculotendinous transfer techniques can improve daily activities [25].

We decided not to propose cervical fixation surgery to our patients because of their young age and the definitive nature of this surgery. We preferred a posterior approach with an extended cervical decompression laminectomy. Our three patients were operated with this technique and their clinical symptoms stabilized or improved. The results of flexion MRI imaging showed a significant expansion of subsequent venous plexus in forward flexion. This posterior compression of venous origin seems to participate in the symptomatology and justified the posterior approach. Moreover, venous congestion is described as being responsible for microcirculation disorder [9]. We decided to decompress all the stenosed levels visible on dynamic T2-weighted MRI. After laminectomy, bipolar coagulation of the venous plexus helped to reduce the compressive flexion phenomenon. This important venous congestion had already been noted by Konno [17] and angiographically demonstrated by Ciceri [26]. Two of the three patients also had a duraplasty to further decompress the spinal cord. It was not performed on the third patient because the dura mater appeared healthy and decompressed intra-operatively.

Our results suggest that we altered the natural course of the disease. All three patients showed clinical and ENMG improvement or stabilization after surgery. Analysis of postoperative MRI showed no recurrence of venous congestion or flexion compression in any of the three patients. Subsequent release and coagulation of the venous plexus, which expands in cervical flexion, appears to be effective in patients affected by Hirayama disease. This strengthens the hypothesis of a venous component in the spinal cord lesion in flexion. Although cervical laminectomy could contribute to kyphotic deformity, we did not find any sign of such outcome: at the last follow-up, none of the three patients had disabling neck pain, while radiological dynamic studies found no evidence of instability.

\section{Conclusion}

We report a case series of three patients with Hirayama disease operated by an original technique of laminectomy with coagulation of the posterior venous plexus in patients. Our findings suggest that this technique may stop the progression of the disease before the disability becomes significant. In view of the previously described techniques of posterior or anterior fusion, the technique described here has the advantage of preserving cervical mobility, which is particularly relevant for these young patients. We believe this technique should be part of the armamentarium available to the surgeon for treating Hirayama disease. However, this series of patients is too small to allow our experience to be generalized to all patients with a similar presentation.

\section{Disclosure of interest}

The authors declare that they have no competing interest.

\section{References}

[1] Hirayama K, Tomonaga M, Kitano K, Yamada T, Kojima S, Arai K. Focal cervical poliopathy causing juvenile muscular atrophy of distal upper extremity: a pathological study. J Neurol Neurosurg Psychiatry 1987;50:285-90.

[2] Tashiro K, Kikuchi S, Itoyama Y, Tokumaru Y, Sobue G, Mukai E, et al. Nationwide survey of juvenile muscular atrophy of distal upper extremity (Hirayama disease) in Japan. Amyotroph Lateral Scler 2006;7:38-45, http://dx.doi.org/10.1080/14660820500396877.

[3] Ben Amor S, Hassine A, Chatti I, Khefifi A, Doggui M, Harzallah MS, et al. Hirayama disease: report of four Tunisian cases and review of literature. Pan Afr Med J 2015;20:380, http://dx.doi.org/10.11604/pamj.2015.20.380.6042.

[4] Correia de Sá M, Costa H, Castro S, Vila Real M. A Portuguese case of Hirayama disease. BMJ Case Rep 2013;2013, http://dx.doi.org/10.1136/bcr-2013-200645.

[5] Dejobert M, Geffray A, Delpierre C, Chassande B, Larrieu E, Magni C. Hirayama disease: three cases. Diagn Interv Imaging 2013;94:319-23, http://dx.doi.org/10.1016/j.diii.2012.10.008.

[6] Rigamonti A, Usai S, Curone M, D’Amico D, Bussone G. Hirayama disease: description of an Italian case. Neurol Sci 2004;25:102-3, http://dx.doi.org/10.1007/s10072-004-0239-y.

[7] Finsterer J, Löscher W, Wanschitz J, Baumann M, Quasthoff S, Grisold W. Hirayama disease in Austria. Jt Bone Spine Rev Rhum 2013;80:503-7, http://dx.doi.org/10.1016/j.jbspin.2012.10.013.

[8] Hirayama K. Juvenile muscular atrophy of distal upper extremity (Hirayama disease). Intern Med Tokyo Jpn 2000;39:283-90.

[9] Hirayama K. Juvenile muscular atrophy of unilateral upper extremity (Hirayama disease) - half-century progress and establishment since its discovery. Brain Nerve Shinkei Kenkyu No Shinpo 2008;60:17-29.

[10] Jin X, Jiang J-Y, Lu F-Z, et al. Electrophysiological differences between Hirayama disease, amyotrophic lateral sclerosis and cervical spondylotic amyotrophy. BMC Musculoskelet Disord 2014;15:349.

[11] Chen C-J, Chen C-M, Wu C-L, Ro L-S, Chen S-T, Lee T-H. Hirayama disease: MR diagnosis. Am J Neuroradiol 1998;19:365-8.

[12] Fujimoto Y, Oka S, Tanaka N, Nishikawa K, Kawagoe H, Baba I. Pathophysiology and treatment for cervical flexion myelopathy. Eur Spine J 2002;11:276-85, http://dx.doi.org/10.1007/s005860100344.

[13] Huang Y-C, Ro L-S, Chang H-S, Chen C-M, Wu Y-R, Lee J-D, et al. A clinical study of Hirayama disease in Taiwan. Muscle Nerve 2008;37:576-82, http://dx.doi.org/10.1002/mus.20980.

[14] Blumen SC, Drory VE, Sadeh M, El-Ad B, Soimu U, Groozman GB, et al. Mutational analysis of glycyl-tRNA synthetase (GARS) gene in Hirayama disease. Amyotroph Lateral Scler Off Publ World Fed Neurol Res Group Mot Neuron Dis 2010;11:237-9, http://dx.doi.org/10.3109/17482960902849823.

[15] Andreadou E, Christodoulou K, Manta P, Karandreas N, Loukaidis P, Sfagos C, et al. Familial asymmetric distal upper limb amyotrophy (Hirayama disease): report of a Greek family. The Neurologist 2009;15:156-60, http://dx.doi.org/10.1097/NRL.0b013e318186717.

[16] Araki K, Ueda Y, Michinaka C, Takamasu M, Takino T, Konishi H. An autopsy case of juvenile muscular atrophy of unilateral upper extremity (Hirayama's disease). Nihon Naika Gakkai Zasshi J Jpn Soc Intern Med 1989;78:674-5.

[17] Konno S, Goto S, Murakami M, Mochizuki M, Motegi H, Moriya H. Juvenile amyotrophy of the distal upper extremity: pathologic findings of the dura mater and surgical management. Spine 1997;22:486-92. 
[18] Kohno M, Takahashi H, Yagishita A, Tanabe H. "Disproportion theory" of the cervical spine and spinal cord in patients with juvenile cervical flexion myelopathy: a study comparing cervical magnetic resonance images with those of normal controls. Surg Neurol 1998;50:421-30.

[19] Biondi A, Dormont D, Weitzner I, Bouche P, Chaine P, Bories J. MR Imaging of the cervical cord in juvenile amyotrophy of distal upper extremity. AJNR Am J Neuroradiol 1989;10:263-8.

[20] Mii K, Shimizu S, Tanaka C, Matsumori K, Hasegawa K, Mizoi Y. Thoracic flexion myelopathy: case report. J Neurosurg 1995;82:1059-61.

[21] Tokumaru Y, Hirayama K. Cervical collar therapy for juvenile muscular atrophy of distal upper extremity (Hirayama disease): results from 38 cases. Rinsho Shinkeigaku 2001;41:173-8

[22] Kohno M, Takahashi H, Ide K, Yamakawa K, Saitoh T, Inoue K. Surgical treatment for patients with cervical flexion myelopathy. J Neurosurg 1999;91: $33-42$.
[23] Watanabe K, Hasegawa K, Hirano T, Endo N, Yamazaki A, Homma T. Anterior spinal decompression and fusion for cervical flexion myelopathy in young patients. J Neurosurg Spine 2005;3:86-91, http://dx.doi.org/10.3171/spi.2005.3.2.0086.

[24] Ito H, Takai K, Taniguchi M. Cervical duraplasty with tenting sutures via laminoplasty for cervical flexion myelopathy in patients with Hirayama disease: successful decompression of a "tight dural canal in flexion" without spinal fusion. J Neurosurg Spine 2014;21:743-52.

[25] Chiba S, Yonekura K, Nonaka M, Imai T, Matumoto H, Wada T. Advanced Hirayama disease with successful improvement of activities of daily living by operative reconstruction. Intern Med 2004;43:79-81.

[26] Ciceri EF, Chiapparini L, Erbetta A, Longhi L, Cicardi B, Milani N, et al. Angiographically proven cervical venous engorgement: a possible concurrent cause in the pathophysiology of Hirayama's myelopathy. Neurol Sci 2010;31:845-8, http://dx.doi.org/10.1007/s10072-010-0405-3. 